\title{
Correspondence
}

\section{NHS morality and care based on compassionate values}

It is difficult to disagree with the main thread of Cox \& Gray's argument that the National Health Service (NHS) as a whole has lost its grip on being person-centred in any genuine way, amidst the industrialisation and authoritarian managerialism of the modern NHS. ' However, I would take issue that the College Centre for Quality Improvement (CCQI) is being idle about the matter.

For over 12 years, I have worked with CCQI staff to set up and develop three projects to promote exactly what Cox and Gray are asking for: robust systems of quality assurance and quality maintenance which focus on the emotional experience of the patients in their particular treatment environments. The Community of Communities quality network for therapeutic communities $^{2}$ started in 2002; the Enabling Environments Award $^{3}$ (which is suitable for any setting) was established in 2009; and the National Enabling Environments in Prisons project began to improve relational-based practice in participating British prisons in 2009. All three projects continue to flourish, and more are planned.

The Enabling Environments Award is based on a set of ten value statements which define 'relational excellence' in work environments. These value statements have been processed to form ten standards, each with several criteria for demonstrating that they have been met. Naturally, compassion and the quality of relationships are at the centre of the expectations. The standards are measured by submission of a portfolio, for which we have designed a flexible and hopefully enjoyable process, rather than a persecutory inspection. Rather than being part of the regulatory burden that many units nowadays feel, our experience to date is that participants take great pride in the process and receiving the resultant award. It is important to note that the award was prominently mentioned in the Royal College of Psychiatrists' report Cox \& Gray are commenting on, OP92: 'The Enabling Environments Award recognises that good relationships promote well-being, but that many organisations and groups fail to address this aspect of people's lives'. ${ }^{4}$ It therefore already forms part of the College's response to the Francis report.

Unfortunately, the response from NHS organisations (mental health and others) has not been encouraging and the award is much better used and recognised in the prison service and all sorts of different third-sector units. I believe this may be caused by a deeper malaise in the NHS, very much in line with what Cox and Gray are arguing in their paper. In short, the NHS is being run with a competitive business model to such an extreme and aggressive extent that 'soft' values such as empathy, emotional intelligence and kindness are given no force.

Related to this, it is worth mentioning that the Institute of Group Analysis, alongside other organisations including the Royal College of Psychiatrists, are running a 6-month listening exercise to gather information from staff across the range of NHS professions and specialties. ${ }^{5}$ When the information is collected and collated, it will be used to negotiate with politicians of all parties in advance of next year's general election. As Cox \& Gray argue, this is a moral question - and a profoundly important one for all of us who want the NHS to survive in a form that we can once again be proud of.

Declaration of interest: R.H. is Enabling Environments Lead, Royal College of Psychiatrists' Centre for Quality Improvement.

1 Cox J, Gray A. The College reply to Francis misses the big question: a commentary on OP92. Psychiatr Bull 2014; 38: 152-3.

2 Haigh R, Tucker S. Democratic development of standards: the community of communities - a quality network of therapeutic communities. Psychiatr Quart 2004; 75: 263-77.

3 Johnson R, Haigh R. Social psychiatry and social policy for the 21st century: new concepts for new needs - the 'Enabling Environments' initiative. Ment Health Soc Inclusion 2011; 15: 17-23.

4 Royal College of Psychiatrists. Driving Quality Implementation in the Context of the Francis Report (OP92). Royal College of Psychiatrists, 2013.

5 Moberly T. Doctors are invited to help improve NHS staff culture. BMJ Careers 2014; 14 Aug.

Rex Haigh is a consultant medical psychotherapist, Upton Hospital, Slough and Framework Lead, Royal College of Psychiatrists' Centre for Quality Improvement, London, UK, email: rexhaigh@nhs.net

doi: $10.1192 / p b .39 .1 .48$

In December 2013, the Royal College of Psychiatrists published an occasional paper responding to the Francis report, OP92. In an editorial, John Cox and Alison Gray stridently criticise the document. $^{2}$ By contrast, I believe that OP92 strikes exactly the right tone and that the actions it sets out should be strongly supported. All members of the College should read it (it is available at the College website: www.rcpsych.ac.uk/files/ pdfversion/OP92.pdf). It succinctly relates principles to the actions that the College is taking.

I suspect that that the source of dissatisfaction for Cox \& Gray lies in the following passages in the document: 'Responses to inadequate or abusive practice tend to emphasise the practical, ethical or moral failings of individuals. These are relevant, but, alone, statements of the importance of compassion, patient-centred care and the duty of candour are unlikely to prevent further scandals. Inadequate and abusive care arises in response to situational forces and a variety of behavioural cues. [ . . . ] We need to take on board the lessons of the Milligram (1974) and Zimbardo (Haney et al, 1973) experiments [ . . . ] namely that ordinary, decent people will behave badly in environments that are not designed to help them to behave well'. ${ }^{(p p . ~ 4-5)}$

This touches on a systemic and empirical understanding of the problems in British healthcare delivery, which is exactly the appropriate approach for applied scientists to take. However, Cox \& Gray seem to prefer a model of moral decay, which they want addressed through urgent dialogue between the College and the medical profession in general on the one hand, and religious leaders and thinkers on the other. They introduce this suggestion through the rhetorical device of an allegation that OP92 fails to address the inadequacies of the 'business model' in healthcare. This criticism is in any case 
inaccurate; OP92 includes an implicit critique of the entire system and the clinical environments it creates, as can be seen in the passages I have quoted.

It is disappointing that Cox \& Gray declare no conflict of interest in their editorial. Four years ago, in a letter to this journal, ${ }^{3}$ they supported a call by Robert Higgo and myself ${ }^{4}$ for the College to establish a working party on psychiatry and religion. Their declaration of interest in that letter was as follows: 'John Cox is a Christian from the Methodist Tradition. Alison Gray was recently ordained Deacon in the Church of England', and their affiliation was stated as 'Centre for Faith Science and Values in Healthcare, University of Gloucestershire'.

Cox \& Gray's religious faith may well help them to adhere to their own moral standards. They have every right to understand things that go wrong in the world in terms of morality and religious faith. These are personal matters. The suggestion that the Royal College of Psychiatrists should take such a position is wholly inappropriate and wrong. The College has important institutional roles concerning ethics and proper professional behaviour, which are part of its overall raison d'être: to maintain and improve standards of care for patients. These roles would be utterly compromised by dabbling in morality and religion. If the College were to take a position on individual morality informed by religious thinking, we would enter a morass of schism and conflict. This would do nothing to protect patients.

Three years ago, concern was raised that the ostensibly anodyne College position paper Recommendations for Psychiatrists on Spirituality and Religion would be taken as permission to breach professional boundaries with respect to religion. ${ }^{5}$ The vast majority of psychiatrists successfully avoid inappropriate interdigitation of faith, belief and professional practice. It will not be just the atheists who will find Cox \& Gray's editorial worrying.

Declaration of interest: I am an atheist.

1 Royal College of Psychiatrists. Driving Quality Implementation in the Context of the Francis Report (OP92). Royal College of Psychiatrists, 2013.

2 Cox J, Gray A. The College reply to Francis misses the big question: a commentary on OP92. Psychiatr Bull 2014; 38:152-3.

3 Cox J, Gray A. Proposed College working party on psychiatry and religion. Psychiatrist 2011; 35: 118.

4 Poole R, Higgo R. Psychiatry, religion and spirituality: a way forward. Psychiatrist 2010; 34: 452-3.

5 Poole R. Praying with patients: belief, faith and boundary conditions. Author's reply. Br J Psychiatry 2011; 199: 518.

Rob Poole is Professor of Social Psychiatry, Centre for Mental Health and Society, Bangor University, Bangor, UK, email: rob.poole@wales.nhs.uk

doi: $10.1192 / p b .39 .1 .48 a$

Authors' reply: We welcome the opportunity to reply to Professor Poole's stimulating and challenging commentary on our editorial which, even if misunderstood, has clearly succeeded in alerting the readership to the pressing managerial and moral challenges for the NHS in the aftermath of the Francis report.

The College, in its 6-month update of its report, has a further chance to unravel the complex contributing circumstances in Mid Staffordshire, and to consider not confining its recommendations to mental health services alone. The failure to put patients first and the neglect of basic quality of care standards could be replicated elsewhere. ${ }^{1}$ The task is not confined to applied scientists, but involves values as well as the personal ethics of members. Therefore, in appearing to belittle the contribution of moral philosophers, comparative religion experts and even patient groups to the consideration of the roots of compassion and to the conceptual underpinning of patient-centred care, Prof. Poole is out of kilter with much local and international work in this field. ${ }^{2}$

We would wish also to counter his suspicion that the source of our dissatisfaction with OP92 was linked to a secret Christian plot to impose our religious values on others of a different faith or none. That was far from our intent - as a detailed, unblinkered reading of the editorial would confirm. Moreover, our earlier disclosures of interest were as cited, but have been repeated without first checking neither their current accuracy, nor the precise context in which those declarations were appropriate. For the interest of readers, J.C. remains a lay member of a Methodist Church in Cheltenham, A.G. is now an associate priest in the Church of England, and the Centre for the study of Faith, Science and Values at the University of Gloucestershire closed last year.

Rex Haigh, on the other hand, is correct to have identified our implicit awareness that the values of the therapeutic community, the understandings of the need for healthy environments respectful of the person - and the grasp of group processes - have each conditioned our search for solutions to the current NHS impasse. The excellent work undertaken by the College's Centre for Quality Improvement (CCQI) was referred to in our editorial and in the College response. It is much to be hoped that the CCQI will increasingly be more integrated with the other College structures, so that its impact on routine medical work in acute hospital care (such as intensive care, a gastrointestinal cancer service or a primary care community unit) can be facilitated. The lack of uptake of the CCQI's projects in the NHS (other than the Quality Network for Perinatal Mental Health Services, which is conspicuously successful $)^{3}$ is, in the context of the Francis recommendations, a cause for much concern and may be symptomatic of the current malaise.

We thank both correspondents for prolonging this timely and important debate. We conclude by declaring an interest in the hope that the College, in tandem with other national organisations, will seek for a majority opinion about the nature of these key structural issues in the NHS - including the fitness for purpose of the competitive business model - and also facilitate a greater understanding of the conceptual (biological, philosophical, ethical, humanistic and religious) underpinning of the nature of health, the process of healing and the primacy of the person.

Declaration of interest: A.G. is a Non-Stipendiary Associate Priest in the Church of England.

1 Dewhurst NG, Jones MC, Wilson JA. Time to refocus the NHS on quality and dignity of patient care: RCPE response to Mid Staffordshire. J R Coll Physicians Edinb 2013; 43; 3-6.

2 Miles A, Mezzich JK. Person-centered medicine: advancing methods, promoting implementation. Int J Pers Centered Med 2011; 3: 423-5.

3 Solomon S, Thomson P. The Quality Network for Perinatal Mental health Services. College Centre for Quality Improvement, 2010.

John Cox, Professor Emeritus, Keele University, UK, email: john1.cox@ virgin.net, and Revd DrAlison Gray, 2gether NHS Foundation Trust, Hereford, UK.

doi: $10.1192 / p b .39 .1 .49$ 